\title{
Perspectives on emerging zoonotic disease research and capacity building in Canada
}

\author{
Craig Stephen DVM PhD ${ }^{1,2}$, Harvey Artsob PhD ${ }^{3}$, William R Bowie MD FRCPC ${ }^{2}$, Michael Drebot PhD ${ }^{4}$, \\ Erin Fraser DVM MSc${ }^{1}$, Ted Leighton PhD DVM ${ }^{5}$, Muhammad Morshed $\mathrm{PhD}^{2}$, Corinne Ong $\mathrm{PhD}^{2}$, \\ David Patrick MD FRCPC MHSc ${ }^{2}$
}

C Stephen, H Artsob, WR Bowie, et al. Perspectives on emerging zoonotic disease research and capacity building in Canada. Can J Infect Dis Med Microbiol 2004;15(6):339-344.

Zoonoses are fundamental determinants of community health. Preventing, identifying and managing these infections must be a central public health focus. Most current zoonoses research focuses on the interface of the pathogen and the clinically ill person, emphasizing microbial detection, mechanisms of pathogenicity and clinical intervention strategies, rather than examining the causes of emergence, persistence and spread of new zoonoses. There are gaps in the understanding of the animal determinants of emergence and the capacity to train highly qualified individuals; these are major obstacles to preventing new disease threats. The ability to predict the emergence of zoonoses and their resulting public health and societal impacts are hindered when insufficient effort is devoted to understanding zoonotic disease epidemiology, and when zoonoses are not examined in a manner that yields fundamental insight into their origin and spread.

Emerging infectious disease research should rest on four pillars: enhanced communications across disciplinary and agency boundaries; the assessment and development of surveillance and disease detection tools; the examination of linkages between animal health determinants of human health outcomes; and finally, cross-disciplinary training and research. A national strategy to predict, prevent and manage emerging diseases must have a prominent and explicit role for veterinary and biological researchers. An integrated health approach would provide decision makers with a firmer foundation from which to build evidence-based disease prevention and control plans that involve complex human/animal/environmental systems, and would serve as the foundation to train and support the new cadre of individuals ultimately needed to maintain and apply research capacity in this area.

Key Words: Emerging disease; Epidemiology; Zoonoses

\section{Perspectives de recherche sur les nouvelle zoonoses et mise en valeur du potentiel canadien}

Les zoonoses sont des déterminants fondamentaux en santé communautaire. Leur prévention, leur dépistage et leur traitement doivent compter parmi les priorités en santé publique. La plupart des projets de recherche actuels sur les zoonoses s'attardent au point de jonction entre l'agent pathogène et la personne cliniquement malade et mettent l'accent sur le dépistage microbien, les mécanismes pathogènes et les stratégies d'intervention clinique plutôt que sur les causes de l'émergence, de la persistance et de la propagation des nouvelles zoonoses. Notre compréhension des facteurs animaux associés à l'émergence des zoonoses est lacunaire, de même que notre capacité de former des personnes hautement qualifiées dans ce domaine. Ce sont des obstacles majeurs à la prévention de nouvelles menaces qui guettent la santé publique. Notre capacité de prédire l'émergence des zoonoses et leurs impacts sociétaux et sanitaires est retardée par le peu d'efforts consacrés à en comprendre l'épidémiologie et par le fait que l'étude actuelle des zoonoses génère peu de données sur leur origine et les raisons de leur propagation.

La recherche sur les maladies infectieuses émergente devrait se fonder sur quatre principes fondamentaux : amélioration des canaux de communication entre les diverses disciplines et agences, évaluation et développement de l'épidémiologie et des outils de dépistage de la maladie, étude des déterminants de la santé animale qui ont un impact sur la santé humaine et finalement, formation et programmes de recherche transdisciplinaires. Les chercheurs en médecine vétérinaire et en biologie devraient pouvoir compter sur une stratégie nationale visant à prédire, prévenir et traiter les maladies émergentes. Une approche intégrée en santé offrirait aux décideurs une base plus solide à partir de laquelle concevoir des plans de prévention et de contrôle rigoureux, tout en tenant compte de la complexité des rapports entre humains, animaux et environnement; cette stratégie orienterait également la formation et le soutien des individus éventuellement chargés de maintenir les programmes de recherche dans ce domaine et d'en appliquer les fruits.
Z oonoses are not merely medical curiosities, but are fundamental determinants of community health. Whether they are newly emerged from animals, or have subsequently adapted to human-to-human transmission, zoonotic diseases have shaped human society. Examples such as the plague in the sixth century, influenza post-World War One and AIDS in modern times show that diseases acquired from animals can cause major demographic and social changes due to their associated rates of mortality and the heavy burden of illness. Zoonotic disease impacts are not, however, restricted to the morbidity and mortality they cause. The past two years have compellingly reinforced their additional impacts on the well being of both rural and urban communities and national economies with diseases such as severe acute respiratory

${ }^{1}$ Centre for Coastal Health, Nanaimo; ${ }^{2}$ University of British Columbia Centre for Disease Control, Vancouver, British Columbia; 3 Zoonotic

Diseases and Special Pathogens; ${ }^{4}$ Viral zoonoses, National Microbiology Laboratory, Health Canada, Winnipeg, Manitoba; ${ }^{5}$ Western College of

Veterinary Medicine, University of Saskatchewan, Saskatoon, Saskatchewan.

Correspondence and reprints: Dr Craig Stephen, Animal Determinants of Emerging Disease Research Unit, Centre for Coastal Health, 900 Fifth

Street, Nanaimo, British Columbia V9R 5S5. Telephone 250-740-6366, e-mail cch@mala.bc.ca

Received for publication August 18, 2004. Accepted September 20, 2004. 
TABLE 1

Key determinants of emerging microbial threats

- Human demographics and behaviour - International travel and commerce

- Technology and industry - Microbial adaptation and change

- Economic development and land use - Breakdown of public health measures

Data from reference 3

syndrome (SARS), mad cow disease and avian influenza. Who would have predicted in 2002 that diseases linked to animals would significantly reduce Canada's economic productivity and the size of the federal government's spending surplus in 2003? These potential impacts are so significant that the second major goal of the Canadian Pandemic Influenza Plan is "to minimize societal disruption among Canadians as a result of an influenza pandemic" (1).

Even without these dramatic recent examples, the ongoing economic effects of zoonoses are tremendous, ranging from lost worker productivity due to food-borne infections to international trade and travel restrictions. The economic costs of food-borne zoonoses in Canada alone have been estimated to be $\$ 1.3$ billion annually (2). Media reports have suggested that the impact on Canadian agriculture from a single case of bovine spongiform encephalopathy (BSE) found in Alberta is nearing multibillion dollar levels. Recent examples of waterborne outbreaks where the failure of routine public health measures led to widespread consequences include toxoplasmosis in the Capital Health Region of British Columbia (spread through the municipal water supply), cryptosporidiosis in North Battleford, Saskatchewan and Escherichia coli O157:H7 in Walkerton, Ontario. Preventing, identifying and managing these infections must therefore be a central public health focus.

Research into and responses to zoonoses have had substantial benefits, contributing to many great advances in public health. Three such examples of this include the role of cowpox in the development of the first human vaccine, the effects of tuberculosis and brucellosis control in establishing food hygiene regulations, and environmental management to prevent the scourge of vector-borne zoonoses. However, current work on zoonoses focuses on the interface of the pathogen and the clinically ill person, emphasizing microbial detection, mechanisms of pathogenicity and clinical intervention strategies rather than examining the causes of emergence, persistence and spread of new zoonoses. Although laudable, these efforts fail to address the complexity of the interplay of human, animal and environmental factors in the emergence and spread of zoonotic diseases.

New problems - due in part to this complexity - will be experienced. All of the determinants of emergence and re-emergence of infectious diseases, highlighted by the Institute of Medicine in its influential 1992 report (Table 1) (3), are anthropogenic factors that are integral components of current society and commerce and not easily amenable to manipulation. Persistence of these drivers ensures that zoonotic and other emerging infections will continue to emerge and disseminate. Some impacts, such as food-borne, water-borne and vector-borne infections due to already known causes, are predictable, while others are less so (although hot spots can be predicted in general terms). As we saw with SARS and HIV, and can expect to see with pandemic influenza, new diseases are most likely to arise outside of Canada, but reach Canada rapidly. However, as with avian influenza in British Columbia, some diseases will arise from within the country.

Canada has a choice to make - either repeatedly be caught unaware and forced to react after a disease has spilled into the human community, or create the ability to anticipate, identify, plan for and rapidly respond to a situation, should one arise. We have shown international leadership in planning for pandemic influenza, but no leadership, indeed, almost no commitment at all, in providing ongoing support for the study of the interactions between animals and humans. Our goals should be to describe and understand the complexities in the Canadian context, and to build and sustain a response capability, including a cadre of trained individuals. An inadequate understanding of the animal determinants of diseases emergence and the inability to train qualified individuals are major obstacles to preventing new disease threats.

Zoonoses or impacts from known zoonoses will not always be specifically predictable. However, both our ability to predict when the next zoonoses may emerge and the impact on individuals and society will be worsened if we have not devoted enough effort to understanding zoonotic disease epidemiology and examined zoonoses in a manner that yields fundamental insight into their origin and spread.

\section{HAS ENOUGH RESEARCH BEEN DEVOTED TO EMERGING ZOONOSES?}

In 2001, Murphy (4) concluded that "the research base for many newly emergent pathogens and the diseases they cause is very small and very narrow... [with] few grants awarded in these subjects". Other authors have suggested that government policies and practices hinder rather than support a program of emerging disease research and response (5). The looming threat of the weaponization of zoonotic pathogens and the recent massive economic impact of diseases like BSE have inspired an influx of additional funds. However, even this increased profile has not changed the field into a major target for funding agencies or academic activity. For example, research funds for veterinary public health remain notoriously difficult to secure in Canada because the subject falls between the mandates of the agencies funding human health and veterinary medicine.

There is a long history of research on zoonoses in Canada, but it has been dispersed in location, subject and continuity. Disparate researchers across the country have completed elegant studies addressing parts of the complex factors that result in an animal pathogen becoming a significant human health threat. However, funding to provide the academic glue to bind these pieces together and allow study of the phenomenon of emergence has not been forthcoming. Funding has typically been clinically or etiologically focused rather than addressing disease emergence and transmission. To date, little funding has been directed toward an integrative approach aimed at finding the fundamental causes of emergence embedded in our relationship with animals. In 1992, the United States Institute of Medicine (3) produced a seminal report that shaped government and funding agencies' attitudes toward the response to emerging diseases. Major emphasis was placed on enhancing laboratory capacity, including infrastructure, communications and training. These recommendations reflect the 'bedside' approach to emerging diseases, where the primary goal is detection and rapid diagnosis of human clinical diseases in the early stages of emergence. A follow-up Institute of Medicine report 
published in 2003 (6) noted a continuing concern from threats of emerging and re-emerging diseases (a large proportion of which are zoonotic), a need to critically address current preventive and remedial measures, and a requirement for further fiscal and political capital to keep pace with the microorganisms.

A cursory review of the Canadian Institutes for Health Research database for selected zoonoses shows that the vast majority of funded research in the past five years has focused on aspects of the pathogen, with a smaller proportion of focus on the host's response, and an even smaller amount on clinical management. From the titles, only two projects appeared to consider interactions of hosts and agents within a systems context. Opportunities for integrative, cross-disciplinary ecological approaches to emerging diseases are therefore currently limited.

Some disease management efforts, such as 'gate-to-plate' food safety programs, examine zoonotic diseases as a continuum from their environmental origins to affected people. A similar continuum that looks from 'stall side-to-bedside' or from 'warren-to-ward' has not been fully applied in emerging disease research. The study of emerging infectious disease requires the participation of several disciplines for reliable prediction and prevention; this is not typically occurring in Canada. Rather than integrating disciplines relevant to the phenomenon of disease emergence, we are isolating them academically, operationally and linguistically. The archaic distinction of the study of patterns of human disease (epidemiology) and animal disease (epizootiology) is an example. Rather than using a systemic program, the task of funding research to collate information and paint a more complete picture of an emerging disease is left to motivated individuals with independent time and resources.

\section{HAVE WE EXAMINED THE PHENOMENON OF EMERGENCE 'PROPERLY'?}

Initial attempts to control zoonoses such as salmonellosis and bovine tuberculosis failed because measures were taken only against clinical cases of the disease (7). Current traditional public health and herd medicine methods have effective techniques to manage endemic zoonoses. However, these methods generally fail to identify specific predictors of emergence. In part, this reflects a lack of field-oriented research focusing on the interactions of multiple hosts, agents and ecologies, as opposed to the specific microbial-focused approach. The population biology of multiple-host infections is poorly understood in comparison with single-host agents, partly reflecting a lack of collaboration between human and animal health professionals. Hardy (8) notes, "Despite warnings of the potential significance for human disease of patterns of changes in the relationship with animals and the natural world, scientists have continued to treat human and animal health as largely independent disciplines".

"Effective analysis of emerging diseases must recognize the study of complexity as perhaps the central general scientific problem of our time," notes Levins (9). The emergence of any new phenomenon results from new properties in a complex system that cannot be reduced to the system's constituent elements (10). The literature on emerging diseases acknowledges the role of ecological and social phenomena. Few studies, however, have the scope and integrative capacity to identify and distill the elements of complex social and ecological systems essential for emergence. In 1996, Koopman (11) suggested that
TABLE 2

Three main features of emergent phenomena

1. Often unpredictable and counterintuitive

2. Seemingly minor changes in the action of one component of the system can have profound effects on the entire system

3. There is not necessarily a logical link between the actions of a single component and the outcome at the group or system level

Data from reference 13

epidemiology was in a transition from a science that identified risk factors to one that analyzes the natural systems that generate patterns of disease in populations. Koopman's advocacy for a systems approach focusing on the underlying interactions that make up the system rather than individual-level risk-factors is well suited to the study of zoonotic diseases. These diseases emerge within a complex mixture of living and nonliving elements whose relationships vary from time to time and place to place. Even the relatively simple task of documenting the impacts of an emerging zoonotic disease requires consideration of the effects from the individual to the farm and to national economies and ecosystems.

Emerging disease forecasting and control is hampered by a lack of basic understanding of the transmission dynamics of zoonotic diseases (12). This makes reliance on standard disease control approaches or intuitive methods for planning disease control impossible, and sometimes unwise, for zoonotic diseases (12). The transmissibility of pathogens and parasites between animals and humans is a key determinant for the emergence of zoonotic pathogens. The nature of transmission is therefore an important subject of scientific inquiry. Many emerging pathogens have complex life cycles and multiple routes of transmission among a variety of hosts. Attempts to control zoonoses can have profound effects on ecosystems (eg, mosquito control for West Nile virus) or economies (eg, banning of antimicrobials for agricultural use). Few public health managers have the experience required to integrate all of the costs and benefits of making disease control recommendations that involve multiple species and multiple sectors. Simple linear models that consider the effects on single actions on specific groups of people is not adequate for comprehensive research on or management of zoonotic disease.

Specific prediction of an entirely new outbreak is likely impossible. In 2002, Bonabeau (13) noted three main features of emergent phenomena (Table 2). Complex systems theorists recognize that parts of a system can react to stimuli or events in unpredictable ways such that relatively small changes in the system can result in disproportionately large effects and vice versa (14). This understanding leads one to become rather pessimistic about our ability to predict the next emerging disease.

In addition, the major drivers of emerging disease are not readily amenable to comprehension, let alone alteration. A broad suite of variables has been associated with emerging diseases: changes in human demographics and behaviour; changes in technology and industry practices; economic development and changes in land-use patterns; increases in international travel and commerce, including movement of people, animals, foodstuffs and other commodities; microbial adaptation and change; and finally, the breakdown of public health capacity (15). All of these variables are vital parts of contemporary global economies and societies. Relying on them as the 
primary predictors of disease emergence is foolhardy, not only because they are too imprecise to allow prediction, but also because it is no longer possible to isolate a country or community from these emergence-associated factors. The frequency of each of these factors occurring without an associated disease emergence far outnumbers the few occasions where disease does emerge. Public health officials working on emerging disease prediction have the delicate task of anticipating a problem without becoming 'Chicken Little' or 'crying wolf'. Incorrectly concluding whether or not an apparently risky situation will result in disease emergence has a large downside. Ironically, successful preventive actions may exacerbate this problem. It is virtually impossible to prove that something was prevented, and equally hard to give credit to the public health workers and brave decision makers who supported the actions.

Increased interconnection has been cited as an underlying reason for the rising tendency of emergent phenomena in society (13). We have increased connections between people and the natural world by concentrating food and water supplies, altering ecosystems previously free of anthropogenic alteration and negating ecological boundaries by travel. We have spent little time studying the social and ecological factors that promote transmissions systems and allow animal pathogens to change from having limited impact on people to becoming major determinants of community and individual health. Enhancing our ability to predict the implications of global climate change on infectious disease rates requires a better understanding of the linkages between meteorological, ecological and epidemiological systems (16). We similarly need to improve the integration of socioeconomic, agricultural, ecological and epidemiological variables that influence our interaction with animals and identify critical control points that can be manipulated to reduce the risk of disease emergence.

\section{WHAT IS THE ULTIMATE GOAL?}

An important question concerning research in emerging zoonoses is, "how precise must our predictions be?" Even with the knowledge of an enormous number of relevant variables, precise prediction is practically impossible. Lederberg (5) concluded, "In the final analysis, it cannot be predicted which zoonotic pathogens are likely to emerge next or cause the biggest problem". A major goal of emerging zoonoses research, then, is to identify consequences and factors that favour disease emergence, thus allowing measures to reduce the risk and emergence as opposed to identifying when and where the next emergence will occur. Because the pathogens are not a random subset of all animal pathogens, risk factors for emergence can be identified. These factors include how we interact with animals and our shared environment (17). Clearly, a single discipline cannot deal with emergence in an effort to reduce mistakes, regardless of whether the focus is on determining the impact of small changes in complex systems or elucidating the nature of interconnection in disease systems.

\section{WHAT DOES CANADA NEED?}

We argue that continually being in a reactive mode is not an adequate Canadian response. There is an obligation to Canadians and, as seen with avian influenza, BSE and SARS, an obligation to the international community to be proactive in better understanding the dynamics of animal-human interactions and their consequences. This requires individuals with the needed skill sets to function collaboratively on a continuing basis, rather than be cobbled together in the midst of the chaos and pressures of outbreak investigation and management. The major goals of such a group or groups should be to critically investigate the complex drivers and interactions of disease emergence through interdisciplinary research, to train a cadre of people with the necessary skill sets, and to serve as a resource to policy makers and other individuals. Ideally, this group should be outside the traditional bureaucracy of ministries or the Canadian Food Inspection Agency, unimpeded by jurisdictional and legislative responsibilities, and within an organizational framework that facilitates creative thinking and open communication.

\section{HOW SHOULD WE APPROACH EMERGING ZOONOSES RESEARCH?}

Health promotion practitioners are increasingly asked to consider the relationships between humans and the nonhuman environment (18). The environment is a key determinant of the sustainability of any population, either human or animal, and influences all aspects of daily living. Indeed, the Ottawa Charter has recognized food, income, a stable ecosystem and sustainable resources as fundamental conditions and resources for health (19). The provision of such resources is often mediated through our relationship with animals. The health effects of human-animal interactions are most acutely revealed through emerging zoonotic diseases. The question that should serve as a cornerstone of emerging zoonoses research is, "Will studies of animal-human relationships allow us to predict and prevent new diseases before they result in measurable health effects, or will we always be forced to react after human health is impacted?" The answer to this question rests on four research pillars: enhanced communications across disciplinary and agency boundaries; assessment and development of surveillance and disease detection tools; examination of linkages between animal health determinants of human health outcomes; and finally, cross-disciplinary training and research.

Regular exchanges of information among animal and human health researchers need to be fostered to permit efficient use of existing knowledge and expertise. The value of enhanced communications between animal and human health workers has been illustrated in several recently emerged diseases in Canada (eg, West Nile virus, avian influenza and cryptococcosis). The inclusion of animal disease data supports a more rapid recognition of the extent and spread of disease. Strengthened interdisciplinary and interagency scientific exchanges and training programs in infectious diseases are priorities for addressing global emerging microbial threats.

The exchange of information presupposes the existence of programs or mechanisms to develop the information. Canada does not lack the intellectual capacity to address emerging disease issues, but neither the academic culture nor the institutional mechanisms exist to synthesize these views to identify the best methods for early detection, prevention and control of emerging illness. The development of an integrated interdisciplinary program requires resources for continuous evaluation and the synthesis of the social, ecological, microbiological and epidemiological factors that influence disease emergence. Theoretical work on integrated risk modelling, collaborative interdisciplinary field research and cross-disciplinary graduate student and educational programs are all means to accomplish this. Most importantly, the formation of a sustained 
interdisciplinary research unit requires collaboration and communication that exist beyond the immediate 'hot topic'.

Any program concerning emerging zoonoses must also deal with three factors in addressing this first element: building intellectual capacity, identifying obstacles to integration and facilitating communications. Few researchers can truly work effectively across species and disciplines. A priority would be to develop opportunities for such highly prized individuals to further develop their skills and expose others to their work models. To prevent research from fragmenting along disciplinary lines, regular venues for researchers to learn and practice interdisciplinary and transdisciplinary studies would be required. Despite the best intentions, there are often institutional obstacles to collaborative work and systems level research and policy. Simply building a research unit will not generate new forms of collaborative work. For longevity and applicability, an emerging zoonoses group must identify and resolve obstacles to a broad approach to infectious disease research that incorporates nonhuman aspects of disease emergence. Because success will depend on linking people of diverse backgrounds working in different agencies, communications between unit members and present or future collaborators will be essential.

The second pillar of research focuses on methods for zoonotic disease detection in humans and surveillance in animals. Surveillance is often taken for granted; it is generally assumed to paint an accurate picture of the health status of populations of interest and is rarely the subject of academic inquiry. But, as with all diagnostic tools, surveillance systems and methods require critical evaluation to validate their effectiveness in determining the risk or disease status of the population or system. There are three key aspects of surveillance of particular relevance to emerging zoonoses: the critical evaluation of systems for emerging animal disease surveillance; the development and validation of novel methods for detecting risks for emergence through observations of animals and animal products; and finally, the discovery of thresholds for action by linking human health outcomes and animal information.

Currently, potential data on infection in animals are often not obtained because the cost is borne privately, and acquiring it exceeds the worth of the animal. Even if obtained, the data are not shared because of proprietary reasons or a lack of means or access to means to disseminate such data. Systematic animal disease surveillance is focused on known diseases of concern for agricultural trade. Research or management resources are seldom directed towards syndromic surveillance in animals, surveillance of diseases not of agricultural concern (such as for companion animals) or surveillance of risk factors. A fundamental methodology and infrastructure for surveillance in fish and wildlife - not to mention companion animals or the full spectrum of potential zoonoses in agricultural species - are lacking. As an interim measure while developing effective and relevant surveillance programs, addressing known diseases with the potential for re-emergence may be a more efficient way to gain insight into the causes of shifting patterns of zoonoses.

There is little hope in enhancing our capacity to identify risk modifications to reduce disease emergence in the absence of the ability to detect changes in animal health before they result in changing human health. The capacity for effective investigation at the earliest suspicion of disease emergence is particularly important when we cannot predict the site or extent of the emergence and ultimate importance of the next new zoonotic pathogen. Substantial effort must be dedicated to secure the cooperation and capacity to detect and investigate new zoonotic diseases through outbreak detection and investigation. In 2001, Stephen and Ribble (20) argued that in animals, outbreaks themselves may be of more value in a sentinel system than disease- or pathogen-specific surveillance. Research efforts must also be dedicated to developing diagnostic tests and evaluating them at an individual and population level because surveillance is built on the capacity to accurately classify the health status of individuals and populations.

The third pillar of research examines how animal health determinants link to human health outcomes. The conclusion that observations in animals can forecast emerging human diseases is based more on analogy and opinion than evidence. Emerging disease forecasting and control is hampered by a lack of fundamental understanding of transmission dynamics of zoonotic diseases (12). It may be pragmatic to begin with a more complete understanding of transmission dynamics and pathogen sharing between people and animals. Our inexperience in incorporating complex systems thinking into the typically linear models used in public health situations is a further limitation - many emerging pathogens have complex life cycles and multiple routes of transmission between a variety of hosts. Additional research must be directed toward how animal and land management decisions modulate human exposure to pathogens. The primary issue in some cases will be the initial movement of the pathogen from animals to people; in other cases, the focus may be on the role of animal-human interactions in maintaining infections in communities.

Advances in our understanding of transmission dynamics can be anticipated through the application of two extremes of epidemiology: molecular and theoretical. Molecular methods can help describe the nature of the 'pool' of shared organisms, help trace the source and spread of organisms between the human and animal communities, and elucidate reasons for the varying expression of pathogens in humans versus animals. New theoretical approaches are increasingly being adapted to infectious disease modelling such as the use of Bayesian analysis, network theory and postnormal systems techniques to generate increasingly accurate information on the population biology of multiple-host infections in complex social and ecological systems (21-23).

The fourth pillar of research seeks to incorporate new concepts of risk assessment, complexity theory and infectious disease ecology into public health research through facilitating training and research that crosses disciplines. Gaps in our understanding of the determinants of disease emergence and in our capacity to train skilled individuals are major obstacles to preventing and responding to new microbial threats. Broadbased, interdisciplinary research and training programs addressing multiple aspects of infectious diseases are needed to moderate the threat of emerging disease (24). Current efforts to incorporate veterinary, medical and biological research are ad hoc and limited to the pressing issue of the day. Many attempts at interdisciplinary research have failed to adequately integrate aspects of animal ecology, animal husbandry or veterinary sciences with research in medical microbiology, sociology and public health. There is currently no academic program in Canada that explicitly and consistently strives to integrate cross-species data in emerging infectious disease research. As well, no academic programs containing a sustained veterinary public health training program exist. These are significant 
gaps, given the role of animals in the majority of recently emerged infectious diseases in North America and abroad.

\section{CONCLUSIONS}

Emerging zoonotic diseases are prime examples of limitations in a patient-focused research agenda. The origins and effects of problematic diseases such as influenza and BSE lie far afield from the bedside. While it is accepted that animals play a role in the emergence and spread of human diseases, the nature, magnitude and importance of animal determinants is based on

\section{REFERENCES}

1. Health Canada. Canadian Pandemic Influenza Plan. Centre for Infectious Disease Prevention and Control. $<$ http://www.phac-aspc.gc.ca/cpip-pclcpi/pdf-cpip-03/ cpip-introduction.pdf> (Version current at November 5, 2004).

2. Health Canada. Development of a centre of expertise for zoonoses/food safety enteric diseases in Health Canada. $<$ http://www.hc-sc.gc.ca/sab-ccs/may1999_appd_drp_e.html> (Version current at October 20, 2004).

3. Institute of Medicine, Shope RE, Oaks SC, Lederberg J, Oaks SC. Emerging Infections: Microbial Threats to Health in the United States. Washington: National Academy Press, 1992.

4. Murphy FA. A perspective on emerging zoonoses. In: Burroughs T, Knobler S, Lederberg J, eds. The Emergence of Zoonotic Diseases: Understanding the Impact on Animal and Human Health. Washington: National Academy Press, 2001:1-9.

5. Lederberg J. Summary and assessment. In: Burroughs T, Knobler S, Lederberg J, eds. The Emergence of Zoonotic Diseases: Understanding the Impact on Animal and Human Health. Washington: National Academy Press, 2001:113-23.

6. Smolinski MS, Hamburg MA, Lederberg J, Institute of Medicine. Microbial threats to health. Washington: National Academy Press, 2003.

7. Bell JC, Palmer SR. Control of zoonoses in Britain: Past, present, and future. Br Med J (Clin Res Ed) 1983;287:591-3.

8. Hardy A. Animals, disease and man: Making connections. Perspect Biol Med 2003;46:200-15.

9. Levins R. Preparing for uncertainty. Ecosystem Health 1995;1:47-57.

10. Possas CA. Social ecosystem health: Confronting the complexity and emergence of infectious diseases. Cad Saude Publica 2001;17:31-41.

11. Koopman JS. Emerging objectives and methods in epidemiology. Am J Public Health 1996;86:630-2.

12. World Health Organization. Future Trends in Veterinary Public Health. <http://whqlibdoc.who.int/trs/WHO_TRS_907.pdf> (Version current at October 20, 2004).

13. Bonabeau E. Predicting the unpredictable. Harv Bus Rev 2002;80:109-16,134. opinion rather than evidence. It is our belief that a national strategy to predict, prevent and manage emerging diseases must have a more prominent and explicit role for veterinary and biological researchers. An integrated health approach would provide decision makers with a firmer foundation from which to build evidence-based disease prevention and control plans that involve complex human/animal/environmental systems. This would serve as the foundation to train and support a new cadre of skilled individuals needed to maintain and apply research capacity in this area.

14. Sweeney K, Kernick D. Clinical evaluation: Constructing a new model for post-normal medicine. J Eval Clin Pract 2002;8:131-8.

15. Hughes JM. Emerging infectious diseases: A CDC perspective. Emerg Infect Dis 2001;7(Suppl 3):494-6.

$<$ http://www.cdc.gov/ncidod/eid/vol7no3_supp/hughes.htm> (Version current at October 20, 2004).

16. National Research Council, Committee on Climate, Ecosystems, Infectious Disease, and Human Health. Under the weather: Climate, ecosystems, and infectious disease. Emerg Infect Dis 2001; 7(Suppl 3). $<$ http://www.cdc.gov/ncidod/eid/vol7no3_supp/geller.htm\#N_1_> (Version current at October 20, 2004).

17. Woolhouse ME. Population biology of emerging and re-emerging pathogens. Trends Microbiol 2002;10(Suppl 10):S3-7.

18. Cole DC, Eyles J, Gibson BL, Ross N. Links between humans and ecosystems: The implications of framing for health promotion strategies. Health Promot Int 1999;14:65-72.

19. WHO, Health and Welfare Canada, and Canadian Public Health Association. Ottawa Charter for Health Promotion, 1996. <http://www.euro.who.int/AboutWHO/Policy/20010827_2> (Version current at November 5, 2004).

20. Stephen C, Ribble C. Death, disease and deformity: Using outbreaks of disease in animals as sentinels for emerging environmental health risks. Global Change and Human Health 2001;2:108-17.

21. Gardner IA. The utility of Bayes' theorem and Bayesian inference in veterinary clinical practice and research. Aust Vet J 2002;80:758-61.

22. Koopman JS. Modeling infection transmission - The pursuit of complexities that matter. Epidemiology 2002;13:622-4.

23. Ancel Meyers L, Newman ME, Martin M, Schrag S. Applying network theory to epidemics: Control measures for Mycoplasma pneumoniae outbreaks. Emerg Infect Dis 2003;9:204-10.

24. National Institute of Allergy and Infectious Diseases. The NIAID research agenda for emerging infectious diseases.

$<$ http://www.niaid.nih.gov/publications/execsum/contents.htm> (Version current at October 20, 2004). 


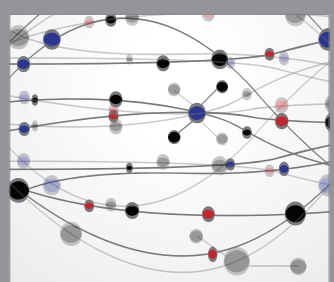

The Scientific World Journal
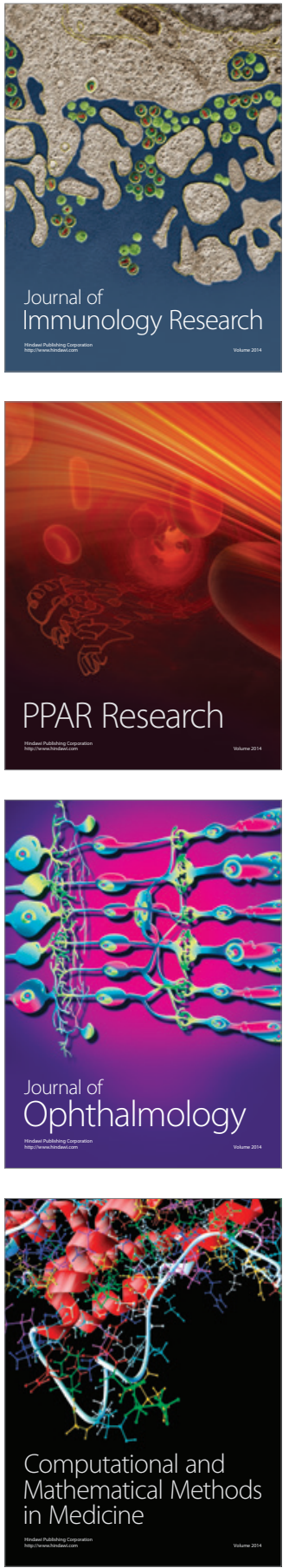

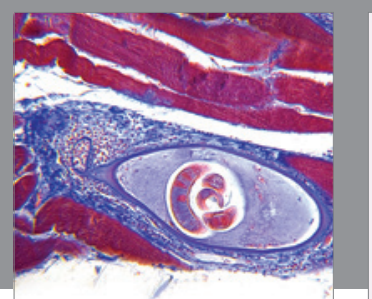

Gastroenterology Research and Practice

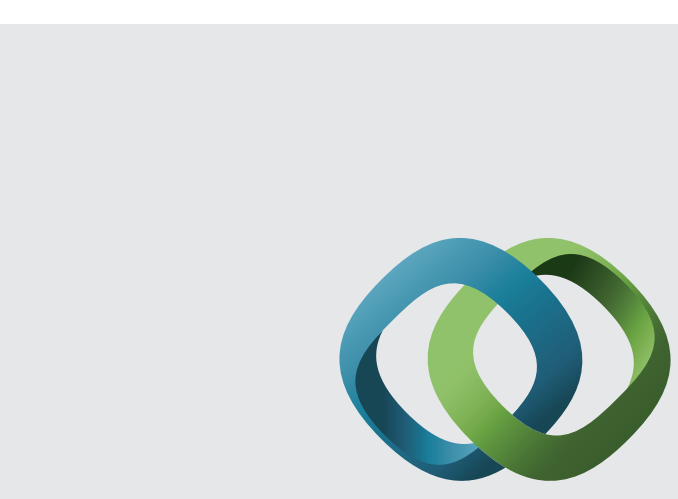

\section{Hindawi}

Submit your manuscripts at

http://www.hindawi.com
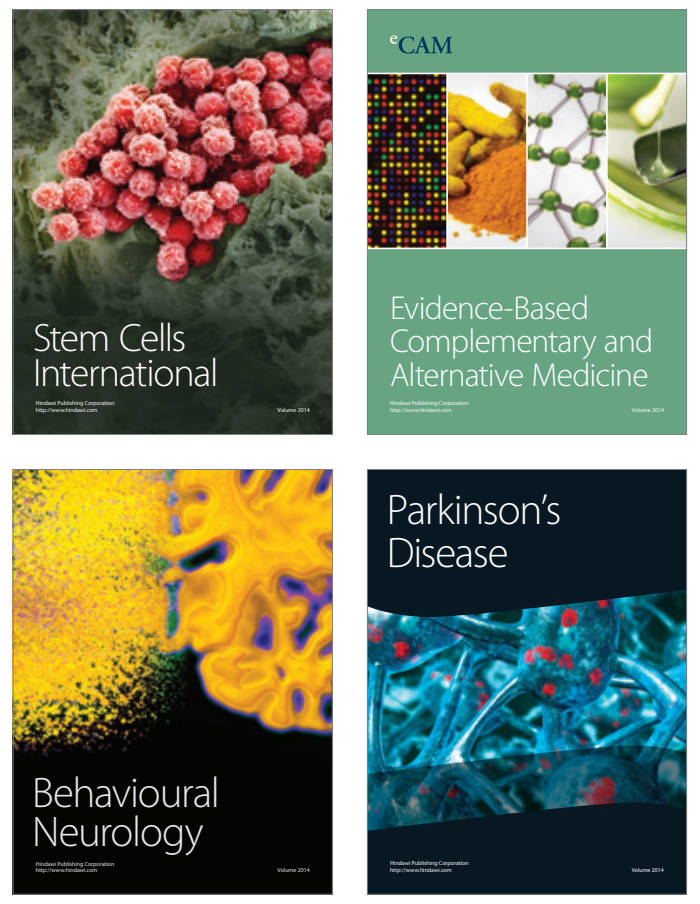
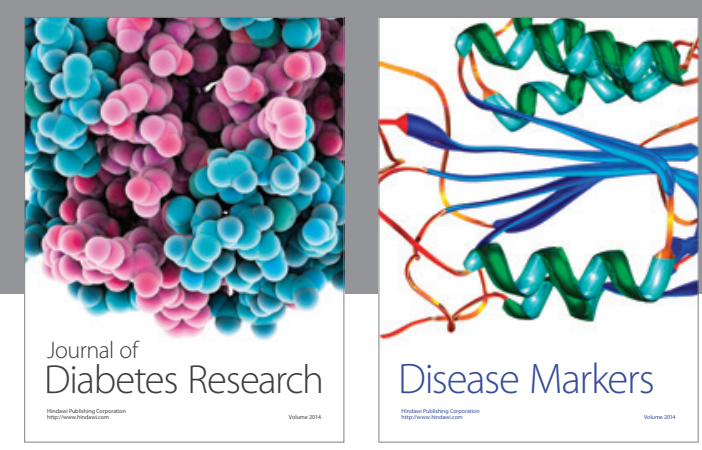

Disease Markers
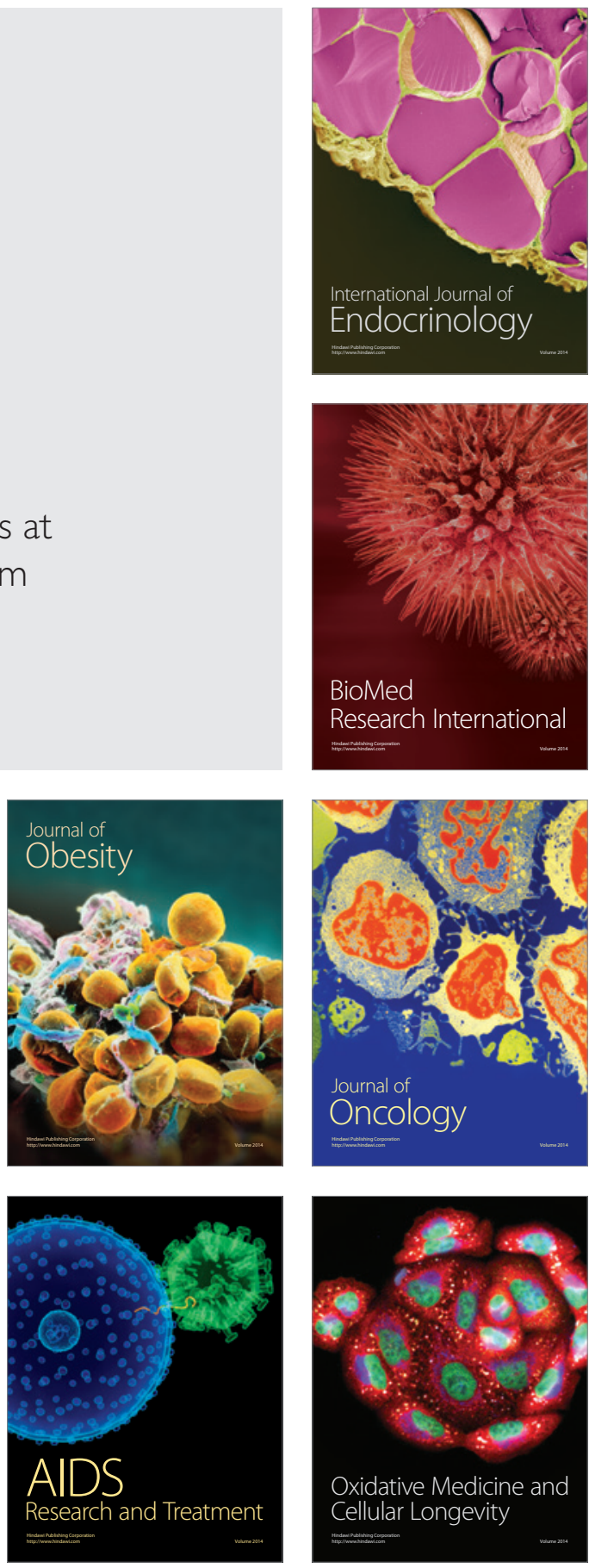